\title{
Lab-scale Evaluation of Two Biotechnologies to Treat VOC Air Emissions: Comparison with a Biotrickling Pilot Unit Installed in the Plastic Coating Sector
}

\author{
F. Javier Álvarez-Hornos, Feliu Sempere, \\ Marta Izquierdo and Carmen Gabaldón \\ GI²AM Research Group, Department of Chemical Engineering, \\ University of Valencia, Burjassot, \\ Spain
}

\section{Introduction}

Volatile organic compounds (VOCs) are one of the top five atmospheric pollutants, and, according to an EC directive, are defined as "all organic compounds arising from human activities, other than methane, which are capable of producing photochemical oxidants by reactions with nitrogen oxides in the presence of sunlight" (Council Directive 2001/81/EC). This definition highlights the fact that VOCs play a vital role in the formation of tropospheric ozone, which causes photochemical smog. Short-term exposure to photochemical smog affects respiratory function and has adverse effects on plants (World Health Organization, 2004). The distinction between biogenic and anthropogenic VOCs in the atmosphere is far from straightforward, because many VOC species are produced by both sources (Popescu \& Ionel, 2010). Anthropogenic sources of VOCs include air emissions from wastewater treatments plants, motor vehicles, gasoline storage facilities and transportation, dry cleaning and other industrial sources (D.J. Kim \& H. Kim, 2005). In this sense, the main sectors involved in non-methane VOC emissions in the EU-27 are solvent and product use (41\%), road and non-road transportation (18\%), and commercial, institutional, and household associated emissions (14\%) (European Environment Agency, 2010). Regarding the industrial sources, Fig. 1 illustrates the contributions from various industrial sectors to EU-27 nonmethane VOC industrial emissions in 2008 (European Pollutant Release and Transfer Register, 2008). The three most important industrial sources are: energy (41\%); the chemical industry (22\%); and coating and surface treatment activities (18\%). In fact, over the past decade, emerging European Union environmental policy has focused on abatement of VOCs from industrial emissions, in an effort to protect environmental and public health. As a result of these initiatives, new European VOC emission limits have been established in the VOC Solvent Emissions Directive (Council Directive 1999/12/EC) for a wide range of industrial sectors. Currently, VOC concentration limits range from 50 to $150 \mathrm{mg} \mathrm{C} / \mathrm{Nm}^{3}$, depending on the application and solvent consumption.

Although process changes and the substitution of solvent-based products for water-based ones have the potential to minimise VOC emissions, stringent VOC emission limits require 


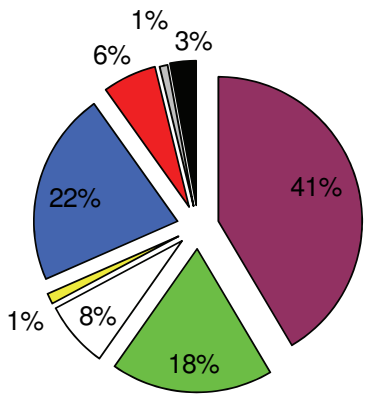

\author{
$\square$ Energy sector \\ $\square$ Coating \& surface treatment activities \\ $\square$ Production and processing of metals \\ $\square$ Mineral industry \\ $\square$ Chemical industry \\ $\square$ Paper and wood production \\ $\square$ Waste \& waste water management \\ - Other activities
}

Fig. 1. Distribution of non-methane VOC industrial emissions in the EU-27 in 2008 by industrial sector (adapted from European Pollutant Release and Transfer Register, 2008).

additional treatment technologies, better known as 'end-of-pipe' techniques. For years, these techniques have been primarily based on non-biological methods, such as condensation, adsorption, absorption/scrubbing and thermal destruction. However, over the last decade, vapour-phase biotechnologies, including biofilters, biotrickling filters and bioscrubbers, have proven to be both efficient and environmentally-friendly for the treatment of VOC emissions, and have been classified as best available technologies (BATs) for the reduction of VOC emissions in the chemical sector by the European IPPC Bureau (European Commission, 2003). Thus, biotechnologies are a potential alternative to conventional physicochemical processes for the removal of VOCs from high flow rate emissions streams with relatively low VOC concentrations: conditions which are common in painting, coating and printing processes. For example, replacing a conventional thermal oxidiser with a biotreatment system for the control of VOC emissions from a panel board press reduced greenhouse gas emissions by 60 to 80 percent, and operating costs by 90 percent (Boswell, 2009).

Vapour-phase biotechnologies are based on the capability of microorganisms of utilizing their metabolism to transform the organic pollutants to less toxic compounds. However, because VOC pollutants are in the air, they must first be transferred from the gas phase to an aqueous phase, where biodegradation can occur. Through biodegradation, contaminants are used as energy and carbon sources for microbial growth, and are converted to carbon dioxide and water. The main vapour-phase biotechnologies available for the treatment of VOC emissions include biofilters (BF), biotrickling filters (BTF) and bioscrubbers (BS). Although the basic VOC removal mechanisms are similar in these systems, there are notable differences with respect to the aqueous phase and microorganism growth, which are summarised in Table 1.

\begin{tabular}{lll} 
Biotechnology system & Microorganism growth & Aqueous phase \\
\hline Biofilter & Attached growth & Stationary \\
Biotrickling filter & Attached growth & Flowing \\
Bioscrubber & Suspended growth & Flowing \\
\hline
\end{tabular}

Table 1. Classification of vapour-phase biotechnology systems. 
Biofilters work by passing polluted pre-humidified air through a porous packed bed of natural organic material, in which a culture of pollutant-degrading microorganisms is developed (Fig. 2 a). The packing material is a key factor for the successful application of biofilters: it is necessary to choose media with adequate physical and chemical properties, such as high surface area, long-term stability, low pressure drop, low-cost, good moisture retention, $\mathrm{pH}$ buffering capacity, appropriate adsorbent capacity and nutrients (Shareefdeen \& Singh, 2005). In addition, because moisture content control is also critical, biofilter systems usually incorporate some kind of water addition. Use of an occasional nutrient supply is also advisable. For biotrickling filters (Fig. 2 b), the polluted air is passed through inert packing material while a liquid stream is re-circulated over the bed. In this case the biofilm is developed on the packing surface, with the liquid phase providing nutrients to the biofilm, allowing for greater $\mathrm{pH}$ control and yielding a more stable operation in comparison with biofilters. These characteristics, along with a larger air/liquid specific surface area, lead to higher VOC removal rates than those obtained with conventional biofilters (Koutinas et al., 2005), suggesting that smaller biotrickling filters can be installed with lower capital investment for industrial applications.

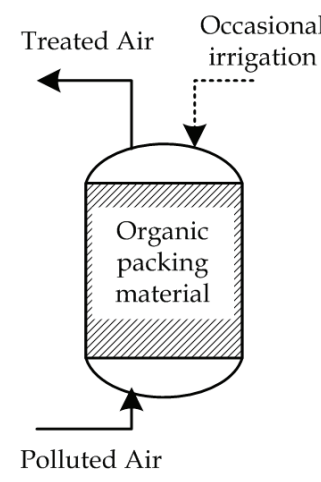

(a) Biofilter

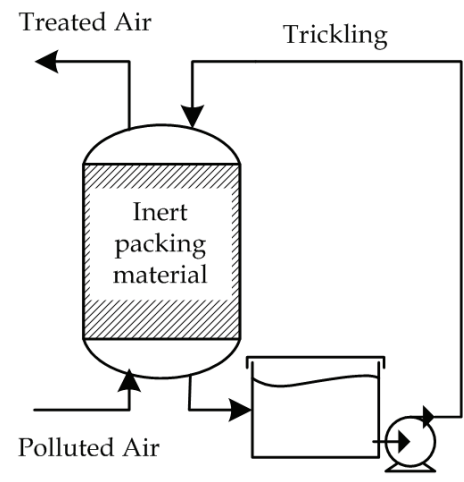

(b) Biotrickling filter

Fig. 2. Schematic of vapour-phase biotechnology systems.

The number of laboratory studies on the control of continuous VOC emissions using biofilters (BF) and biotrickling filters (BTF) has significantly increased over the last two decades. These studies have mainly focused on evaluating process performance as a function of the operational conditions (e.g. gas empty bed residence time, inlet load or nutrient formulation and concentration), and/or packing material characteristics, with the aim of obtaining valuable information from these biological technologies. BFs and BTFs have been applied in the treatment of streams contaminated with a wide variety of pollutants, including oxygenated compounds (Cox \& Deshusses, 2001; Steele et al., 2005), aromatics (Hwang et al., 2008; Kennes et al., 1996), or its mixtures (Paca et al., 2006; Sempere et al., 2008).

However, studies dealing with the removal of complex VOC mixtures from painting and coating processes using BFs or BTFs are limited, especially for pilot/full-scale units. Emissions from these processes typically result in streams with high flow rates and relatively low VOC concentrations, which usually contain a complex mixture of 
hydrophobic (e.g. toluene and xylenes) and hydrophilic (e.g. n-butyl acetate, ethyl acetate and methyl propyl ether) compounds. Concerning laboratory scale experiments, Mathur \& Majumder (2008) investigated methyl ethyl ketone (MEK), toluene, n-butyl acetate and oxylene elimination using a coal-based BTF, and reported a maximum elimination capacity (EC) of $185 \mathrm{~g} \mathrm{~m}^{-3} \mathrm{~h}^{-1}$ for an inlet load (IL) of $278 \mathrm{~g} \mathrm{~m}^{-3} \mathrm{~h}^{-1}$, working at an empty bed residence time (EBRT) of $42.4 \mathrm{~s}$. Similarly, Higuchi et al. (2010) observed a maximum EC of $87.5 \mathrm{~g} \mathrm{~m}^{-3} \mathrm{~h}^{-1}$ for removal of 2-butanone, butyl acetate, butoxyl, toluene, ethylbenzene and xylene, using a BTF packed with poly-vinyl formal (PVF) material operated at an inlet concentration of $0.43 \mathrm{~g} \mathrm{~m}^{-3}$ and an EBRT of $12 \mathrm{~s}$. These data indicate that, although biofiltration is suitable in terms of overall VOC removal and has shown significant potential, it still requires additional optimisation. It is thus essential to assess BFs and the BTFs in real situations using pilot scale units, with the aim of obtaining valuable and useful information necessary for scale-up. Webster et al. (1999) installed a $0.47 \mathrm{~m}^{3}$-volume BTF pilot unit to treat off-gases from two spray paint booths, achieving removal efficiency (RE) higher than $70 \%$ working at an EBRT between 11 and $39 \mathrm{~s}$ for the target pollutants: MEK, methyl isobutyl ketone, o-xylene, m-xylene, pxylene and n-butyl acetate. Martinez-Soria et al. (2009) evaluated introduction of an activated carbon prefilter in the treatment of VOC emissions from spray paint booths in the wood furniture industry, using a $0.75 \mathrm{~m}^{3}$-volume BTF pilot unit: the prefilter buffered VOC fluctuations, ensuring that legal limits were met while working at an EBRT of $24 \mathrm{~s}$.

This chapter presents studies conducted to assess environmentally friendly biotechnologies, such as biofilters and biotrickling filters, for VOC abatement in air at two scales. First, a laboratory-scale study was designed to investigate the use of a biofilter (BF) and a biotrickling filter (BTF) under continuous feeding conditions, for VOC removal from air contaminated with three compounds commonly found in air emissions from paint and coating processes: $n$-butyl acetate, toluene and m-xylene (a 2:1:1 weight mixture was used to simulate exhaust gases). These compounds have been previously identified as representative VOCs in paints (Boswell et al., 2001). Second, a biotrickling filter pilot unit was used to assess treatment of exhaust gases from a robotic spray paint booth at a plastic coating facility (located in Soria, Spain), which is a supplier of car mirrors to the automotive sector. The performance of this pilot-scale BTF was compared with results obtained from the lab-scale systems.

\section{Materials and methods}

Two experimental phases were carried out during this research: (1) laboratory scale experiments using both biofilter and biotrickling filter, and (2) pilot-scale operation of a biotrickling unit connected to a robotic spray paint booth at a plastic coating facility.

\subsection{Laboratory-scale systems}

Treatment of air polluted with a 2:1:1 (wt) n-butyl acetate:toluene:m-xylene mixture was studied both in a biofilter and in a biotrickling filter at the laboratory scale.

A schematic of the laboratory-scale biofilter set-up is shown in Fig. 3. The lab-scale BF was made of methacrilate, with a total length of $97 \mathrm{~cm}$ and an internal diameter of $13.6 \mathrm{~cm}$. The $\mathrm{BF}$ was equipped with 5 equidistant sampling ports to measure VOC concentrations, and four additional ports for temperature measurements and filter bed sampling. Fibrous peat (ProEco Ambiente, Spain) was used as the filter material. Because the peat was acidic, the $\mathrm{pH}$ was adjusted to neutral using a diluted sodium hydroxide solution. Compressed, 
filtered and dried-air was passed through two serial-humidifiers, to assure a relative humidity of $\geq 90 \%$. The EBRT was adjusted using a mass flow controller (Bronkhorst Hi-Tec, The Netherlands). Pollutant was introduced to the air stream using a syringe pump (New Era, infusion/withdraw NE 1000 model, USA) and then, air polluted with the VOC mixture was flowed downward into the bed.

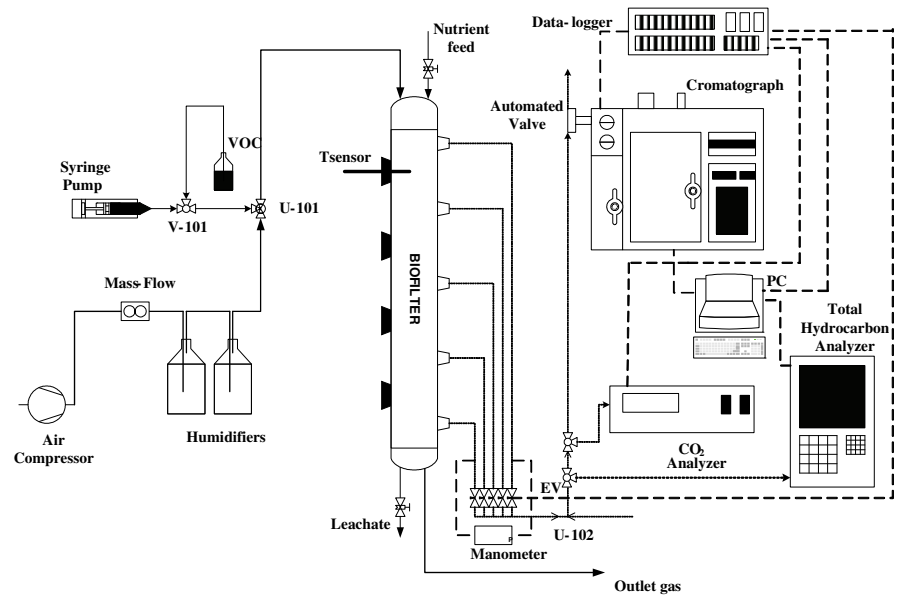

Fig. 3. Schematic of the laboratory-scale biofilter (BF).

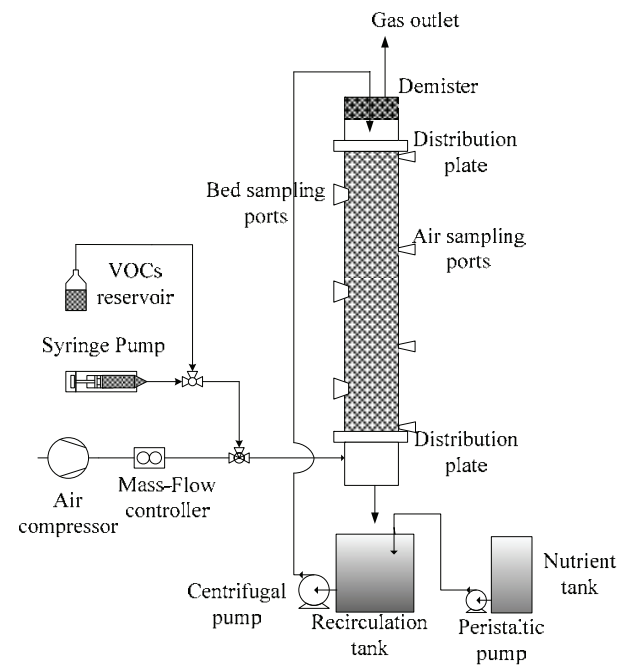

Fig. 4. Schematic of the laboratory-scale biotrickling filter (BTF).

A schematic of the laboratory-scale biotrickling filter is shown in Fig. 4. The lab-scale BTF was composed of 3 cylindrical modules of Plexiglas, with a total bed length of $120 \mathrm{~cm}$ and an internal diameter of $14.4 \mathrm{~cm}$, and was equipped with a recirculation tank (effective volume, $10 \mathrm{~L}$ ). The BTF was randomly filled with 1-inch of nominal diameter Flexiring ${ }^{\mathrm{TM}}$ 
polypropylene rings (Koch-Glistch B.V.B.A., Belgium). Compressed, filtered and dried-air air was polluted with VOCs as above, using a syringe pump (New Era, infusion/withdraw NE 1000 model, USA). Then, VOC contaminated air was introduced through the bottom of the column, and the flow rate was adjusted using mass flow controllers (Bronkhorst Hi-Tec, The Netherlands). The recirculation stream was introduced counter to the air flow, and was partially renewed (50 - 100\% of total volume) every week.

The main properties of the peat and Flexiring ${ }^{\mathrm{TM}}$ ring packing materials used in the $\mathrm{BF}$ and the BTF set-ups, respectively, are shown in Table 2.

\begin{tabular}{lc}
\hline \multicolumn{1}{c}{ Fibrous peat } \\
\hline Organic content, \% wt & 95 \\
BET specific surface area, $\mathrm{m}^{2} \mathrm{~g}^{-1}$ & 13.4 \\
$\mathrm{pH}$ & 4.8 \\
Bulk density, $\mathrm{kg} \mathrm{m}^{-3}$ & 133 \\
Water-holding capacity, \% wt & 88 \\
Shape & Fibres \\
Fibre length, cm & $2-8$ \\
\hline \multicolumn{2}{c}{ Flexiring } \\
\hline Specific surface area, $\mathrm{m}^{2} \mathrm{~m}^{-3}$ & 207 \\
Void fraction, \% & 92 \\
Bulk density, $\mathrm{kg} \mathrm{m}{ }^{-3}$ & 71 \\
Shape & Rings \\
Ring diameter, $\mathrm{cm}$ & 24.5 \\
\hline
\end{tabular}

Table 2. Physical and chemical properties of the packing materials.

The necessary macro and micronutrients were incorporated using a $\mathrm{pH}$ buffered nutrient solution containing $\mathrm{N}\left(3 \mathrm{~g} \mathrm{~L}^{-1}\right), \mathrm{P}\left(0.6 \mathrm{~g} \mathrm{~L}^{-1}\right), \mathrm{Ca}, \mathrm{Fe}, \mathrm{Zn}, \mathrm{Co}, \mathrm{Mn}, \mathrm{Mo}, \mathrm{Ni}$ and $\mathrm{B}$ at trace doses. The nutrient solution was incorporated in the biofilter by directly pouring $100 \mathrm{~mL}$ per day on the top the column and was supplied to the biotrickling filter using a peristaltic pump, whose flow rate was adjusted to keep nitrogen concentrations $>10 \mathrm{mg} \mathrm{L}^{-1}$ in the recirculation solution.

The two bioreactors were inoculated with a mixed microbial culture (obtained from activated sludge which was adapted to the compounds to be treated). For acclimation of the microbes, the VOC mixture was continuously fed to an activated sludge from the secondary clarifier of Carraixet Wastewater Treatment Plant (located in Alboraya, Spain), for a period of at least two months in order to obtain an adapted inoculum. The Carraixet treatment plant receives urban sewage from Alboraya town and pollutants from the Alboraya industrial site. Inoculation of the BF was performed by mixing the peat with a $1 \mathrm{~L}$ of the inoculum. For the BTF, $1.5 \mathrm{~L}$ of the inoculum was added into the recirculation tank.

The BF and the BTF were operated under continuous feeding conditions for a total period of 4 months and 3 months, respectively. For the BF, an EBRT of $60 \mathrm{~s}$ (gas flow rate of $0.85 \mathrm{~m}^{3}$ $\mathrm{h}^{-1}$ ) and an IL of $19 \mathrm{~g} \mathrm{C} \mathrm{m}^{-3} \mathrm{~h}^{-1}$, corresponding to an inlet total VOC concentration of 300 mg C Nm${ }^{-3}$, were applied. For the BTF, 6 experiments, each with duration of 2 weeks, were performed at an EBRT between 60 and $15 \mathrm{~s}$ (gas flow rate between 1.2 and $4.7 \mathrm{~m}^{3} \mathrm{~h}^{-1}$ ) for IL varying from 11 to $72 \mathrm{~g} \mathrm{C} \mathrm{m}^{-3} \mathrm{~h}^{-1}$, corresponding to VOC concentrations between $160 \mathrm{mg} \mathrm{C}$ $\mathrm{Nm}^{-3}$ and $350 \mathrm{mg} \mathrm{C} \mathrm{Nm}^{-3}$. 


\subsubsection{Analytical techniques}

The total VOC concentration was measured by using a total hydrocarbon analyser equipped with an FID detector (Nira Mercury 901 model, Spirax-Sarco, Spain). The composition of the gas streams were monitored using a gas chromatograph (7890 model, Agilent Technologies, USA) equipped with a $1.0 \mathrm{~mL}$ automated gas valve injection system, a flame ionisation detector and an HP-5 capillary column $(30 \mathrm{~m} \times 0.32 \mathrm{~mm} \times 0.25 \mu \mathrm{m}$, Agilent Technologies, USA). The gas carrier was helium, and a flow-rate of $9.4 \mathrm{ml} \mathrm{min}{ }^{-1}$ was used. The injector, oven and detector temperatures were 180,50 and $250{ }^{\circ} \mathrm{C}$, respectively.

$\mathrm{CO}_{2}$ concentrations in the influent and effluent gas streams were periodically determined using a CARBOCAP ${ }^{\circledR}$ carbon dioxide analyser (GM70 model, Vaisala, Finland). The pressure drop was monitored daily with a digital manometer (KIMO, MP101 model, Spain). Temperature and $\mathrm{pH}$ were also measured daily for the biofilter leachate. The moisture content of the biofilter media was determined once a week at two locations (upper and lower), using the dry weight method. Similarly, the conductivity and $\mathrm{pH}$ of the BTF recirculation solution were analysed daily. Soluble chemical oxygen demand (COD), suspended solids, and nitrate concentrations in the recirculation solution were periodically measured.

\subsection{Pilot-scale unit}

The pilot-scale plant was supplied by Pure Air Solutions B.V. (The Netherlands). Pure Air Solutions has developed a biotrickling pilot-scale unit, using its innovative abatement technology (VOCUSTM Biotrickling Filter System). A schematic of this unit is presented in Fig. 5. The biological reactor, a column with a volume of $0.75 \mathrm{~m}^{3}$, was randomly filled with two inches of nominal diameter FlexiringTM propylene rings (Koch-Glistch B.V.B.A., Belgium), with a $93 \%$ void fraction. The bioreactor was operated in counter-current mode. VOC polluted air from the factory was introduced below the column at a flow rate between 34 and $90 \mathrm{~m}^{3} \mathrm{~h}^{-1}$. Recirculated water was poured on the top of the filter media at a flow rate of $1.2 \mathrm{~m}^{3} \mathrm{~h}^{-1}$ and the spraying frequency was fixed at 20 minutes per hour. The trickled

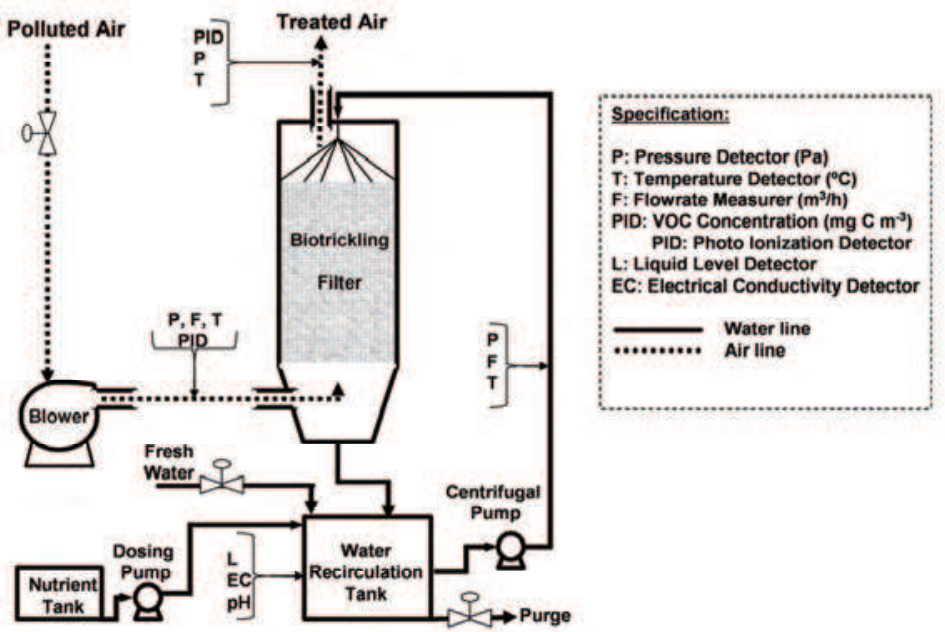

Fig. 5. Schematic of the pilot-scale biotrickling filter unit (VOCUSTM). 
water was collected in a $0.4 \mathrm{~m}^{3}$ recirculation tank. The liquid level of this tank was controlled, so that fresh water was added when the level of water decreased as a consequence of evaporation. Recycled water was fully drained and replaced with fresh water once a month. A nutrient dosing system composed of a $100 \mathrm{~L}$ nutrient vessel and a dosing pump was set-up in the pilot unit. The nutrient solution $\left(\mathrm{pH}=7,3 \mathrm{~g} \mathrm{~N} \mathrm{~L}^{-1}, 0.6 \mathrm{~g} \mathrm{P}\right.$ $\mathrm{L}^{-1}$, trace elements) was added to the recirculation tank at a maximum rate of $0.15 \mathrm{~L} \mathrm{~h}^{-1}$ in order to achieve a $\mathrm{C}_{\text {degraded }} / \mathrm{N}_{\text {supplied }}$ mass ratio above $30-40$. The system was equipped with a programmable logic controller, and a set of sensors and devices enabling control and monitoring of the plant via modem communication.

The pilot-scale biotrickling system was inoculated with activated sludge from the municipal Wastewater Treatment Plant (located in Soria, Spain) without further acclimation, in order to simulate operational protocols at an industrial site. An inoculum volume of $100 \mathrm{~L}$ was added to the recirculation tank and continuously flowed through the bed for 72 hours.

At the plastic coating facility, rear view mirrors for cars are coated in three serial robotic spray booths (primer, base coat and clear coat layers). From the three existing sources of VOC emissions, the clear coating spray booth was selected as the focus for this work. The gaseous emissions from this booth were piped to the pilot unit, and contained a mixture of oxygenated and aromatic compounds coming from the applied product formulation (a mixture of a specific clear coat with its thinner) in the coating process. The pilot-scale unit was operated at EBRTs between 30 and 80 seconds (air flows between 34 and $90 \mathrm{~m}^{3} \mathrm{~h}^{-1}$ ) over a period of 3 months, in order to determine the minimum EBRT value that enables legal regulations to be met (emission limit value (ELV): an average value of $75 \mathrm{mg} \mathrm{C} \mathrm{Nm}^{-3}$ for all valid readings, with none of the hourly averages exceeding the ELV by more than a factor of 1.5).

\subsubsection{Analytical techniques}

Inlet and outlet gas temperatures, inlet and outlet total VOC concentrations (measured using two photo ionisation detectors, or PIDs), air flow, the pressure drop between the gas inlet and the outlet of the media bed, tank levels, and the conductivity, $\mathrm{pH}$ and temperature of the trickling solution were continuously monitored. A total hydrocarbon analyser (Nira Mercury 901 model, Spirax-Sarco, Spain) was periodically used to check and calibrate the PIDs sensors. Samples of the recirculated water were collected to analyse COD, suspended solids and nitrogen and phosphorus content.

\subsection{Parameters for characterisation of biodegradation performance}

In general, the performance of the above described biotechnologies is evaluated using the parameters defined below:

Empty bed residence time (s):

$$
E B R T=V_{f} / Q
$$

where $\mathrm{Q}=$ air flow rate $\left(\mathrm{m}^{3} \mathrm{~s}^{-1}\right)$ and $\mathrm{V}_{\mathrm{f}}=$ filter bed volume $\left(\mathrm{m}^{3}\right)$.

Removal efficiency (\%):

$$
R E=100 \cdot\left(1-C_{o} / C_{i}\right)
$$

where $C_{i}$ and $C_{o}=$ inlet and outlet pollutant concentration, respectively $\left(\mathrm{g} \mathrm{Nm}^{-3}\right)$. 
Inlet load $\left(\mathrm{g} \mathrm{m}^{-3} h^{-1}\right)$ :

$$
I L=C_{i} Q / V_{f}
$$

Elimination capacity $\left(\mathrm{g} \mathrm{m}^{-3} h^{-1}\right)$ :

$$
E C=\left(C_{i}-C_{0}\right) Q / V_{f}
$$

\section{Results and discussion}

\subsection{Laboratory-scale systems}

The performance parameters of both biotechnologies are summarised in Table 3 for the different stages of the experimental plan. The performance of each unit during the entire operation period is shown in Fig. 6, illustrating the different stages described in Table 3. The evolution of inlet and outlet total VOC concentrations and the total removal efficiency (RE) for the biofilter and biotrickling filter are plotted in Fig. 6 (a) and 6 (b), respectively. The average temperature in the reactors was $25.3 \pm 1.6$ and $21.2 \pm 2.3^{\circ} \mathrm{C}$ for $\mathrm{BF}$ and $\mathrm{BTF}$, respectively. Biofilter leachate $\mathrm{pH}$ was maintained at approximately $5.8 \pm 0.2$, while the $\mathrm{pH}$ and conductivity of the BTF recirculation solution were $8.7 \pm 0.3$ and $4.3 \pm 1.4 \mathrm{mS} \mathrm{cm}^{-1}$, respectively. Pressure drop ranged from 330 to $500 \mathrm{~Pa} \mathrm{~m}^{-1}$ for the $\mathrm{BF}$ unit, and from 40 to 280 $\mathrm{Pa} \mathrm{m}^{-1}$ for the BTF system, indicating the absence of clogging. Soluble COD values for the BTF recirculation solution were periodically analysed, and were stable at approximately 154 $\pm 56 \mathrm{mg} \mathrm{L}^{-1}$, representing less than $2 \%$ of the weekly inlet load fed to the system. Therefore, the organic carbon quantity removed in the purge was considered negligible. For the BF unit, the moisture content of the media (a key parameter for optimum biofilm development), was maintained at appropriate values and a slight stratification was observed: values (wet basis, \%wt) varied between $78.4 \% \pm 2.9 \%$ in the upper zone and $80.7 \%$ $\pm 1.7 \%$ in the lower zone of the bed.

\begin{tabular}{lccccc}
\hline & Days & EBRT, $\mathrm{s}$ & $\mathrm{IL}, \mathrm{g} \mathrm{C} \mathrm{m}^{-3} \mathrm{~h}^{-1}$ & $\mathrm{EC}, \mathrm{g} \mathrm{C} \mathrm{m}^{-3} \mathrm{~h}^{-1}$ & $\mathrm{RE}, \%$ \\
\hline $\begin{array}{l}\text { Biofilter } \\
\text { Stage BF1 }\end{array}$ & $0-112$ & $60.0 \pm 1.3$ & $18.8 \pm 1.5$ & $17.7 \pm 1.4$ & $94.1 \pm 2.7$ \\
$\begin{array}{l}\text { Biotrickling filter } \\
\text { Stage BTF1 }\end{array}$ & $0-12$ & $59.1 \pm 0.1$ & $11.2 \pm 0.8$ & $8.5 \pm 0.8$ & $74.6 \pm 6.4$ \\
Stage BTF2 & $12-36$ & $59.1 \pm 0.1$ & $21.1 \pm 1.9$ & $11.5 \pm 1.7$ & $54.8 \pm 7.6$ \\
Stage BTF3 & $36-50$ & $30.0 \pm 0.3$ & $19.6 \pm 1.4$ & $13.0 \pm 1.4$ & $66.0 \pm 2.5$ \\
Stage BTF4 & $50-63$ & $30.0 \pm 0.3$ & $31.7 \pm 2.9$ & $21.2 \pm 3.3$ & $66.6 \pm 4.4$ \\
Stage BTF5 & $63-79$ & $15.1 \pm 0.7$ & $39.6 \pm 1.7$ & $21.2 \pm 2.4$ & $53.5 \pm 5.4$ \\
Stage BTF6 & $79-92$ & $15.1 \pm 0.7$ & $72.4 \pm 1.2$ & $32.7 \pm 1.3$ & $45.3 \pm 2.2$ \\
\hline
\end{tabular}

Table 3. Operational and performance parameters for both systems on the different stages.

After inoculation, both systems were operated at an approximate EBRT of $60 \mathrm{~s}$, with moderate ILs (18.8 and $11.2 \mathrm{~g} \mathrm{C} \mathrm{m}^{-3} \mathrm{~h}^{-1}$ for BF and BTF, respectively). High and stable REs were reached in 2 - 5 days for both bioreactors, indicating appropriate development of the inoculum. For the BF unit, total REs remained at very high values (as high as 97\%) throughout the entire experimental period. In the case of the BTF unit, no complete removal 
was obtained, even for the lower applied IL (stage BTF1), due to the low removal of toluene and $\mathrm{m}$-xylene in comparison with the complete degradation of n-butyl acetate. Kinney \& Moe (2004) also observed lower biodegradability of aromatic compounds in the treatment of gas emissions contaminated with 2-pentanone, n-butyl acetate, ethyl 3-ethoxypropianate, toluene and p-xylene, using a biotrickling filter. The decrease in the EBRT caused a progressive drop in the total RE of the BTF system. For example, at an inlet VOC concentration of approximately $170 \mathrm{mg} \mathrm{C} \mathrm{Nm}^{-3}$, average RE values decreased from 75 to $54 \%$ for EBRTs ranging from 59 to $15 \mathrm{~s}$ (stages BTF1 and BTF5, respectively). At this concentration, the BTF was able to meet legal limits (ELV), even for the lowest EBRT (IL of $39.6 \mathrm{~g} \mathrm{C} \mathrm{m}^{-3} \mathrm{~h}^{-1}$, stage BTF5). Similarly, the total RE was negatively affected when the inlet VOC concentration was duplicated. In this case, total RE values increased slightly, from 45 to $54 \%$, when IL was dropped from 72.4 to $39.6 \mathrm{~g} \mathrm{C} \mathrm{m}^{-3} \mathrm{~h}^{-1}$ (stages BTF6 and BTF5, respectively).
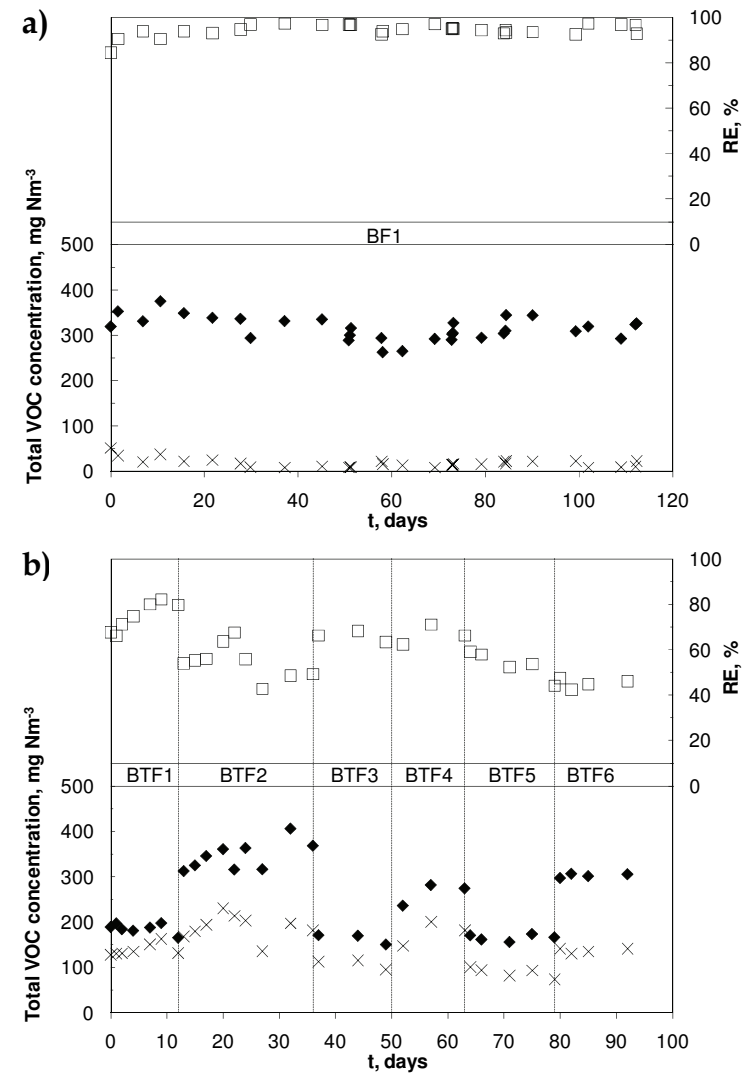

Fig. 6. Evolution of inlet VOC concentrations ( $\bullet)$, outlet VOC concentrations ( $\mathrm{X})$ and total RE values ( $\square$ ) in (a) BF and (b) BTF with time.

The variation of EC with IL at different EBRTs for the biofilter and the biotrickling filter is plotted in Fig. 7. ECs were calculated from the top of the bioreactors to each sampling port 
(first quarter, half, three-quarters and total bed volume for the BF; and first third, two-thirds and total bed volume for the BTF). Maximum ECs for both systems were estimated from data taken from the first section of the bed. $\mathrm{EC}$ values were nearly directly proportional to the total IL of the VOC mixture: up to $50 \mathrm{~g} \mathrm{C} \mathrm{m}^{-3} \mathrm{~h}^{-1}$ for the BF, and $20 \mathrm{~g} \mathrm{C} \mathrm{m}^{-3} \mathrm{~h}^{-1}$ for the BTF. No significant differences between both biotechnologies were observed for the maximum EC values. A maximum EC value of $45 \mathrm{~g} \mathrm{C} \mathrm{m}^{-3} \mathrm{~h}^{-1}$ was obtained for both systems. It is worth noting the slight influence of the applied EBRT (which ranged between 15 and 60 s) on EC values for the applied IL in the biotrickling filter.

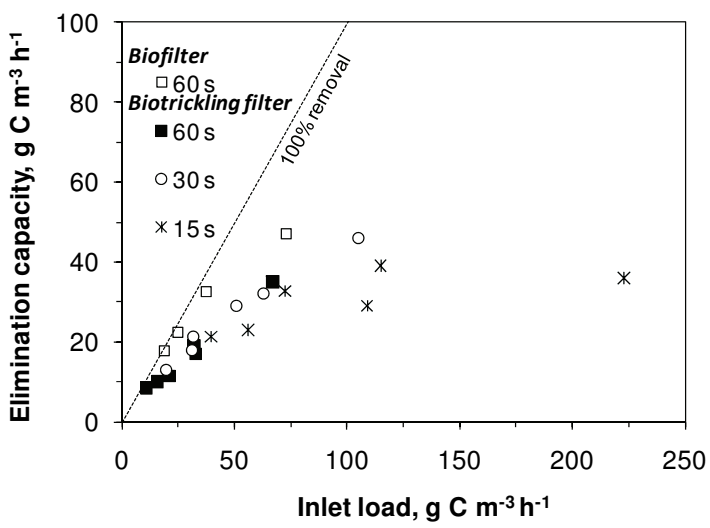

Fig. 7. Variation of EC vs. IL at different EBRTs for the biofilter and biotrickling filter.

The evolution of $\mathrm{CO}_{2}$ production as a function of elimination capacity (EC) is presented in Fig. 8 for both biotechnologies. A proportional ratio exists between $\mathrm{EC}$ and $\mathrm{CO}_{2}$ production. As can be seen, the biofilter datum follows the same trend as the biotrickling filter results. Linear regression of these data yielded a value of $1.74 \mathrm{~g} \mathrm{CO}_{2} \mathrm{~g} \mathrm{C}^{-1}$. Assuming a general biomass composition formula of $\mathrm{C}_{5} \mathrm{H}_{7} \mathrm{O}_{2} \mathrm{~N}$, and negligible organic and inorganic carbon removal during the periodic purges, overall yield coefficient (defined as $\mathrm{g} C$ of dry biomass synthesised per $\mathrm{g} \mathrm{C}$ of substrate consumed) can be determined from the following biodegradation reaction balance:

$$
\mathrm{C}_{\mathrm{x}} \mathrm{H}_{\mathrm{y}} \mathrm{O}_{\mathrm{z}}+\mathrm{aO}_{2}+\mathrm{NH}_{3} \longrightarrow \mathrm{bC}_{5} \mathrm{H}_{7} \mathrm{O}_{2} \mathrm{~N}+\mathrm{cCO}_{2}+\mathrm{dH}_{2} \mathrm{O}
$$

yielding a value of 0.53 .

The degradation of each of the three compounds of the VOC mixture is shown in Fig. 9, where normalised pollutant gas concentration profiles along the bed length of the BF and BTF have been plotted. For the BTF, concentration profiles from the three highest ILs are shown. As can be seen in the Fig. 9, complete removal of n-butyl acetate was always observed in the first twothirds of the bioreactors for all stages. Greater penetration was observed for aromatic compounds, with individual removal efficiencies of approximately $30 \%$ for each aromatic compound in the first quarter of the $\mathrm{BF}$, whereas no degradation of these compounds was obtained in the first third of the BTF. Among aromatic compounds, greater emissions were observed for m-xylene, which is less biodegradable than toluene. Previous studies have reported similar phenomena (Álvarez-Hornos et al., 2007; Paca et al., 2006). 


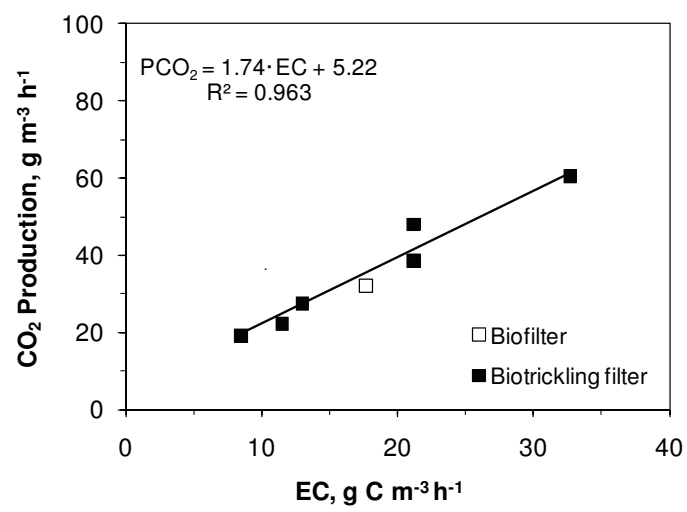

Fig. 8. The relationship between $\mathrm{EC}$ and $\mathrm{CO}_{2}$ production for both biotechnologies.
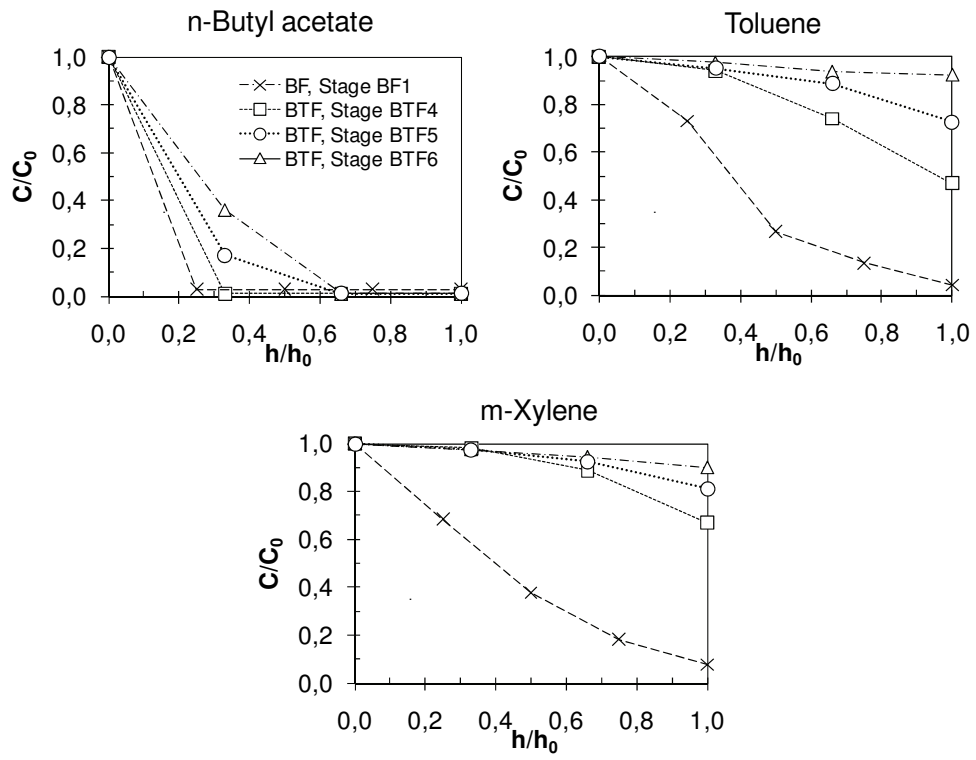

Fig. 9. Pollutant concentration profiles along the length of the BF and BTF.

\subsection{Pilot unit}

\subsubsection{Characterisation of emissions from the spray paint booth}

The industrial site operates full-time, 24-hours a day, from 6:00 am on Monday to 6:00 am on Saturday, with shut down periods during weekends. Gas flow rate for the emissions coming from the clear coating spray booth was approximately $35000 \mathrm{Nm}^{3} \mathrm{~h}^{-1}$, with daily average emission temperatures ranging between 8 and $22{ }^{\circ} \mathrm{C}$ throughout the experimental period. The VOC concentration was relatively stable during working hours, with hourly average values ranging between 100 and $450 \mathrm{mg} \mathrm{C} \mathrm{Nm}^{-3}$, and with a daily average concentration of $235 \pm 57 \mathrm{mg} \mathrm{C} \mathrm{Nm}^{-3}$. A typical VOC concentration emission pattern from the booth system 
over one working day is shown in Fig. 10. As can be seen, because the inlet hourly average VOC concentration exceeded the ELV by a factor greater than 1.5 (maximum hourly legal limits), treatment of booth emissions may be required.

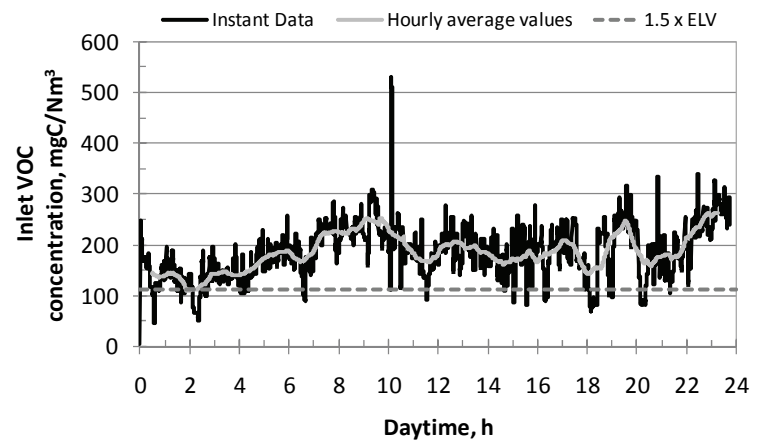

Fig. 10. Typical instant and hourly VOC concentration emission patterns from the booth system. The discontinuous line represents a factor of 1.5 of the ELV.

GC-MS analyses of both emission samples and samples of the solvents used in the coating process detected the following compounds: oxygenated compounds such as butyl acetate, butyl glycol acetate and methyl acetate (comprised $>70 \%$ ); and solvent naphtha including small proportions of aromatics compounds. The two product formulations used by the facility during the experimental period are summarised in Table 4.

\begin{tabular}{ccc} 
& Product A & Product B \\
\hline \multirow{2}{*}{$\begin{array}{c}\text { Clear coat } \\
(70 \% \text { wt) }\end{array}$} & xylene $10-25 \%$ & butyl glycol acetate $25-50 \%$ \\
& 2-methoxy-1-methylethyl acetate $10-25 \%$ & naphtha, light aromatic $10-25 \%$ \\
Isobutyl acetate $10-25 \%$ & naphtha, heavy aromatic $10-25 \%$ \\
Thinner & 1,2,4-trimethyl benzene $2.5-10 \%$ \\
$(30 \%$ wt $)$ & n-butyl acetate $100 \%$ & n-butyl acetate $25-50 \%$ \\
& & butyl glycol acetate $10-25 \%$ \\
& & 1,2,4-trimethyl benzene $2.5-10 \%$ \\
& & naphtha, light aromatic $2.5-10 \%$ \\
\hline
\end{tabular}

Table 4. Product formulations used for the clear coating process during the experimental period.

\subsubsection{Pilot unit performance}

After inoculation, the pilot unit was operated at an approximate EBRT of $20 \mathrm{~s}$. During the first month, a progressive increase in removal efficiency was observed until stable performance was achieved. Once the system was stable, the air flow rate through the system was periodically adjusted to values of $33.8,60,41.5$ and $90 \mathrm{Nm}^{3} \mathrm{~h}^{-1}$, corresponding to EBRTs of $80,65,45$ and 30, respectively. In Fig. 11, (a) to (d), the inlet and outlet hourly average VOC concentrations obtained during a typical day of operation are plotted for the four EBRTs applied. 

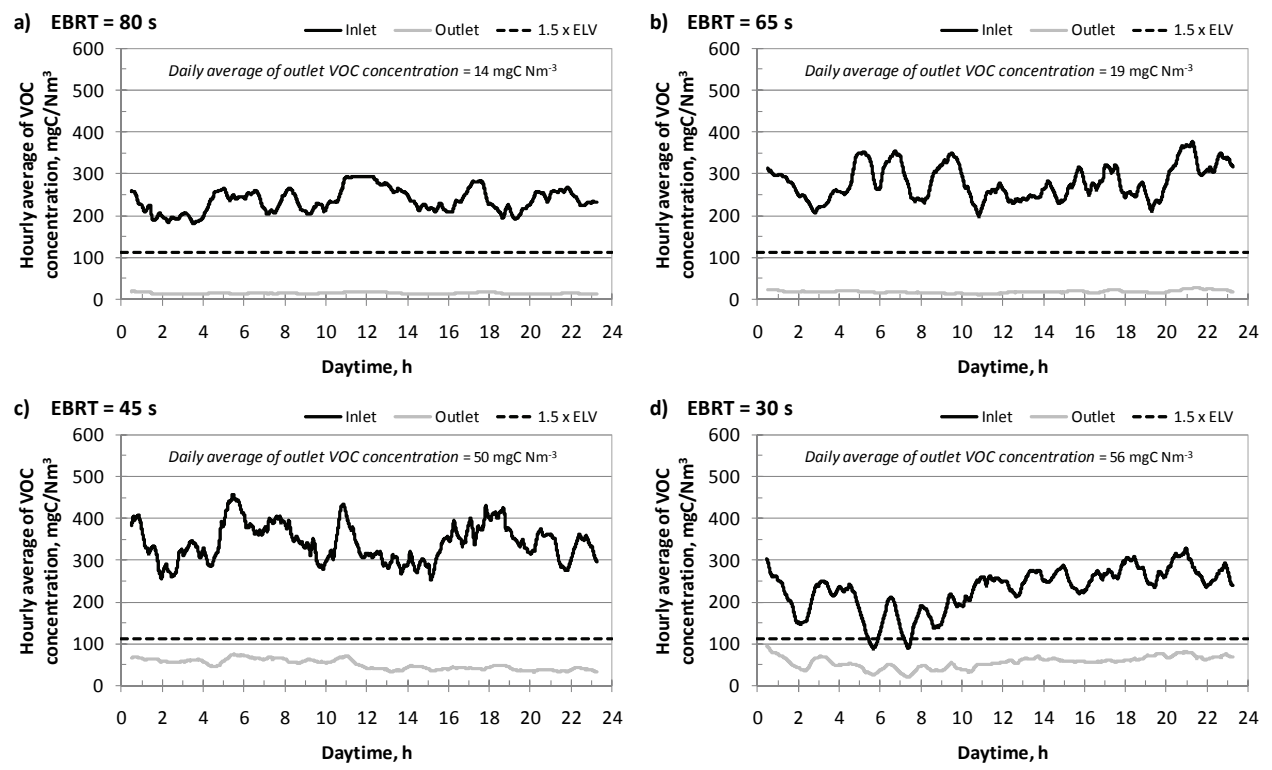

Fig. 11. Daily pilot unit monitoring at four EBRTs: hourly average values working at an EBRT of (a) $80 \mathrm{~s}$, (b) $65 \mathrm{~s}$, (c) $45 \mathrm{~s}$ and (d) $30 \mathrm{~s}$. The discontinuous line represents a factor of 1.5 times the ELV.

As can be seen, outlet emissions met legal regulations for all of the tested EBRT, with daily average values of $14,19,50$ and $56 \mathrm{mg} \mathrm{C} \mathrm{Nm}^{-3}$, for 80,65, 45 and $30 \mathrm{~s}$ of EBRT, respectively. Therefore, with respect to legal compliance, bioreactor performance was not significantly affected by the decrease in the EBRT. It is worth noting that outlet emissions did not exceeded the legal limit after the facility started the coating process on Monday mornings after weekend shutdown periods (data not shown here).

Fig. 12 summarises the performance of the pilot unit during the test period. The variation of overall RE versus the four applied EBRTs is presented in Fig. 12 (a). The variation of the daily average outlet concentration versus the daily average inlet concentration as a function of the tested EBRT is shown in Fig. 12 (b). As can be seen in Fig. 12 (a), the overall removal efficiency was not significantly affected (RE values were between 85 and 95\%) when the pilot unit was operated with EBRTs ranging between 45 and $80 \mathrm{~s}$. However, RE dropped to approximately $70 \%$ when the EBRT decreased to $30 \mathrm{~s}$. Still, the lowest EBRT (30 s) was enough to maintain outlet VOC concentrations below legal limits $\left(75 \mathrm{mg} \mathrm{C} \mathrm{Nm}^{-3}\right)$, despite the observed decrease in RE (see Fig. 12 (b)). Furthermore, when the pilot unit was operated at an EBRT > $45 \mathrm{~s}$, the outlet concentration was always in compliance with the ELV over the entire inlet concentration range. Therefore, the minimum EBRT value that would allow legal regulations to be met within an adequate safety margin is between 35 and $40 \mathrm{~s}$.

The pressure drop in the pilot unit was low $\left(<60 \mathrm{~Pa} \mathrm{~m}^{-1}\right)$ during the entire test period, indicating that the short-term starvation periods during weekend closures, combined with the relatively low VOC inlet load $\left(\sim 25 \mathrm{~g} \mathrm{C} \mathrm{m}^{-3} \mathrm{~h}^{-1}\right)$ avoided clogging episodes in the reactor. Soluble COD values measured in the recirculation liquid varied between 200 and $300 \mathrm{mg}$ COD $\mathrm{L}^{-1}$, representing $<1 \%$ of the inlet organic carbon fed to the pilot unit. The $\mathrm{pH}$ and conductivity average values of the recirculation liquid were 7.2 and $1.0 \mathrm{mS} \mathrm{cm}^{-1}$, respectively. 

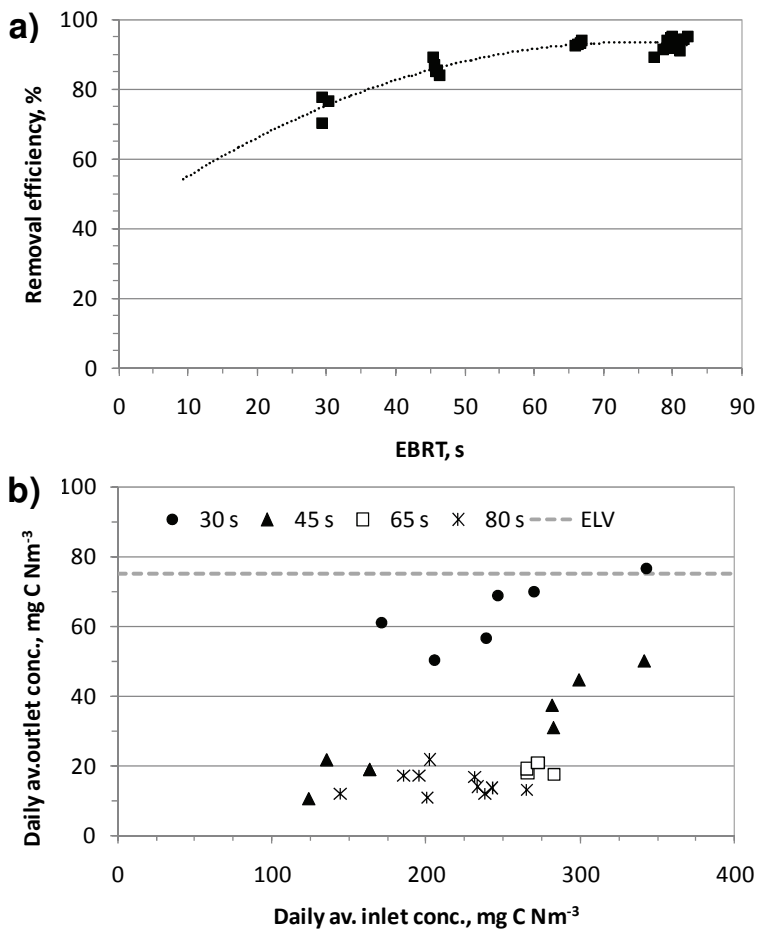

Fig. 12. Summary of pilot unit performance during the entire experimental period: (a) Overall RE vs. EBRT and (b) Daily average outlet concentration vs. daily average inlet concentration.

\subsubsection{Comparison with laboratory-scale biotechnologies}

A comparison of the pilot-scale unit performance with results obtained from the laboratoryscale biofilter and biotrickling filter (used to treat a continuous VOC emission polluted with a 2:1:1 (wt) n-butyl acetate:toluene:m-xylene mixture) is shown in Fig. 13. The variation in RE versus EBRT for the pilot unit, biofilter and biotrickling filter, for every section of the bed height, is presented in Fig. 13 a. Results from the biotrickling filter correspond to an inlet VOC concentration of approximately $200 \mathrm{mg} \mathrm{C} \mathrm{Nm}^{-3}$ (stage BTF1, BTF3 and BTF5), similar in magnitude to the industrial VOC emission at the pilot unit. The variation of EC with IL for all data obtained from the three systems is plotted in Fig. 13 (b).

As can be seen, results obtained from the pilot-scale unit match those from the laboratoryscale experiments. The slightly better performance of the pilot unit versus the lab-scale BTF may be due to the following: (1) the oxygenated compound composition tested in the pilotscale industrial emission ( $>70 \%)$ was higher than that tested in the laboratory-scale BTF unit (50\%); (2) greater variability in the organic composition of the industrial emission could have derived from a more complex microbial ecosystem; and (3) the short-term starvation periods due to weekend closures at moderate operational conditions could help to improve the activity of the biological system (Wright et al., 2005). Importantly, comparison between the laboratory-scale and pilot-scale units indicate that laboratory studies could be a timesaving tool for obtaining valuable data for scale-up. 

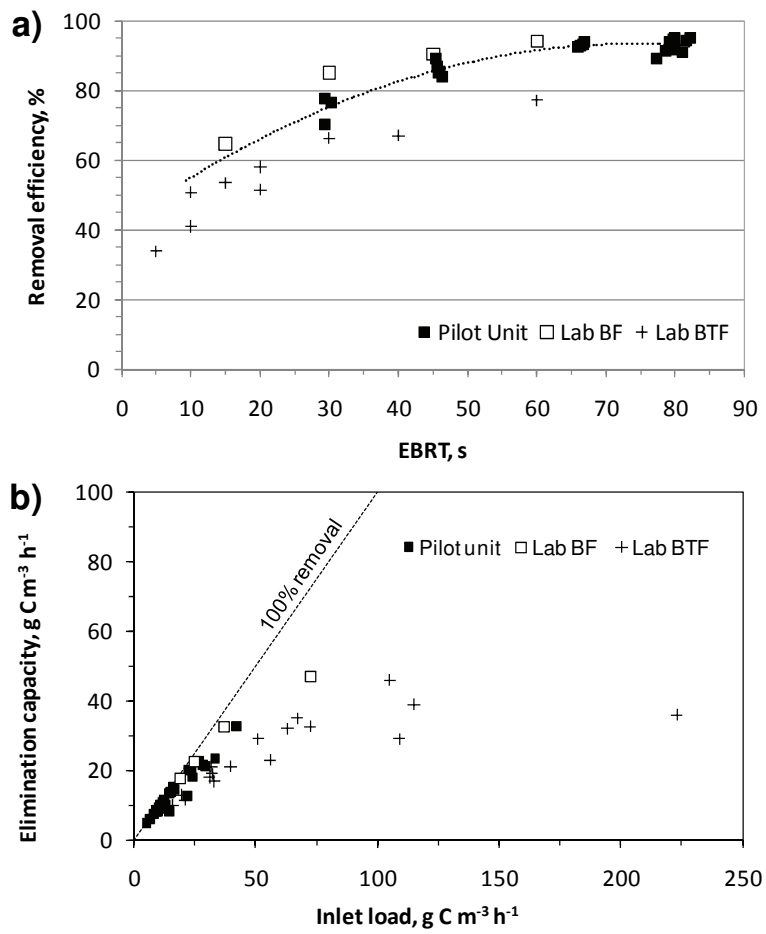

Fig. 13. Comparison of the performance of the pilot unit with results obtained from the laboratory-scale biofilter and biotrickling filter: (a) Overall RE vs. EBRT and (b) EC vs. IL.

\section{Conclusions}

Biological removal of VOCs from exhaust gases from a robotic spray paint booth at an industrial plastic coating facility has been studied. The present work evaluated the performance of environmentally friendly biotechnologies, such as biofilters and biotrickling filters, on a laboratory-scale; for comparison with a biotrickling filter pilot-scale unit connected to an industrial facility. Treatment of air contaminated with three compounds typically found in air emissions from paint and coating processes (n-butyl acetate, toluene and m-xylene) was conducted using the laboratory-scale systems. Although the biofilter displayed a higher removal efficiency than the biotrickling filter during the test period, a similar maximum elimination capacity of $45 \mathrm{~g} \mathrm{C} \mathrm{m}^{-3} \mathrm{~h}^{-1}$ was estimated for both laboratory biotechnologies. Results from the laboratory-scale experiments demonstrate the slight influence of the applied EBRT (which ranged between 15 and $60 \mathrm{~s}$ ) on the EC for the applied IL in the biotrickling filter. However, application of EBRTs lower than $60 \mathrm{~s}$ to the BF would cause greater drying of the organic packing material, resulting in a decrease in the removal efficiency. Because of the higher EBRTs required, industrial scale biofilter applications would require greater sizes, and therefore higher investment costs. Moreover, BTF units are compatible with $8-10 \mathrm{~m}$ high bioreactors, enabling construction of units with smaller footprints than comparable BF units. In addition, it is also worth noting that the pressure drop in the BTF unit $\left(<60 \mathrm{~Pa} \mathrm{~m}^{-1}\right)$ was lower than that observed in the $\mathrm{BF}$ (around $400 \mathrm{~Pa} \mathrm{~m}^{-1}$ ), due to the larger void fraction of the inert 
packing material: this difference in pressure drop is significant, because lower values require less power consumption from the blower equipment. Although complete removal of n-butyl acetate was achieved in both cases, aromatic compounds penetrated throughout the bed, indicating that mechanisms of gas removal for hydrophilic and hydrophobic compounds may be significantly different. Our evaluation of the operation of the pilot-scale plant for 3 months demonstrates the suitability and robustness of the biological process for controlling VOC emissions from a robotic spray paint booth. Importantly, legal emission limits were always achieved for the four tested empty bed residence times (EBRTs). The minimum EBRT required to meet legal regulations appears to be between 35 and $40 \mathrm{~s}$. From an engineering perspective, comparison of the laboratory-scale and pilot-scale units indicates that laboratory-scale studies could be a timesaving tool for obtaining valuable data to establish safe operation limits which should allow legal requirements to be met.

\section{Acknowledgments}

Financial support from the Ministerio de Ciencia e Innovación (Spain, research projects CTM2010-15031 and TRA2009_0135) is acknowledged. F. J. Álvarez-Hornos acknowledges Ministerio de Educación, Spain, for providing a post-doctoral contract by means of Programa Nacional de Movilidad de Recursos Humanos del Plan Nacional de I+D+i 2008-2011. The authors would like to give special thanks to Pure Air Solutions and FICOMIRROR, SA (Ficosa International Group) for their consistent collaboration and support.

\section{References}

Álvarez-Hornos, F.J., Gabaldón, C., Martínez-Soria, V., Marzal, P., Penya-roja, J.M. \& Izquierdo, M. (2007). Long-term performance of peat biofilters treating ethyl acetate, toluene, and its mixture in air. Biotechnology $\mathcal{E}$ Bioengineering, Vol.96, pp. 651-660, ISSN 0006-3592

Boswell, J.T., John, P.C., Stewart, B., Forrest, S., Branchik, R. \& Morgan, S. (2001). Biofiltration of VOCs from Paint Manufacturing, Proceedings of AEWMA's 94th Annual Meeting \& Exhibition, Orlando, USA, June 24-28, 2001

Boswell, J. (2009). Clearing the air: the use of bio-oxidation for industrial air emissions control. Engineered Wood Journal, Fall, pp. 26-28

Cox, H.H.J. \& Deshusses, M.A. (2001). Biotrickling filters, In: Bioreactors for waste gas treatment, C. Kennes \& M.C. Veiga (Ed.), 99-131, Kluwer Academic Publisher, ISBN: 978-0-7923-7190-8, Dordrecht, The Netherlands

European Commission (2003). IPPC Reference document on Best Available Techniques in common waste water and waste gas treatment/management systems in the chemical sector, Sevilla, Spain

European Environment Agency (2010). European Union emission inventory report 1990-2008 under the UNECE Convention on Long-range Transboundary Air Pollution (LRTAP). EEA Technical report 7/2010, ISBN 978-92-9213-102-9, Copenhagen, Denmark

European Pollutant Release and Transfer Register (2008). Available from http://prtr.ec.europa.eu/

Higuchi, T., Morita, Y. \& Minato, R. (2010). Biofiltration of the exhaust gas contaminated by six VOC compounds for testing the feasibility of its application to a painting process, Proceedings of the 2010 Duke-UAM Conference on Biofiltration for Air Polllution Control, pp. 273-278, Washington, USA, October 28-29, 2010 
Hwang, J.W., Choi, C.Y. \& Park, S. (2008). Biodegradation of gaseous styrene by Brevibacillus sp. using a novel agitating biotrickling filter. Biotechnology Letters, Vol.30, pp. 1207-1212, ISSN 0141-5492

Kennes, C., Cox, H.H.J., Doddema, H.J. \& Harder, W. (1996). Design and performance of biofilters for the removal of alkylbenzene vapors. Journal of Chemical Technology and Biotechnology, Vol.66, pp. 300-304, ISSN 1097-4660

Kim, D.J. \& Kim, H. (2005). Degradation of toluene vapor in a hydrophobic polyethylene hollow fiber membrane bioreactor with Pseudomonas putida. Process Biochemistry, Vol.40, pp. 2015-2020, ISSN 1359-5113

Kinney, K.A. \& Moe, W.M. (2004). Optimization of an innovative biofiltration system as a VOC control technology for aircraft painting facilities, Final report - SERDP Project CP 1104. Air Force Research Laboratory, Tyndal AFB, EEUU.

Koutinas, M., Peeva, L.G. \& Livingston, A.G. (2005). An attempt to compare the performance of bioscrubbers and biotrickling filters for degradation of ethyl acetate in gas streams. Journal of Chemical Technology and Biotechnology, Vol.80, pp. 12521260, ISSN 1097-4660

Martínez-Soria, V., Gabaldón, C., Penya-roja, J.M., Palau, J., Álvarez-Hornos, F.J., Sempere, F. \& Soriano, C. (2009). Performance of a pilot-scale biotrickling filter in controlling the volatile organic compound emissions in a furniture manufacturing facility. Journal of the Air \& Waste Management Association, Vol.59, pp. 998-1006, ISSN 10473289

Mathur, A.K. \& Majumder, C.B. (2008). Biofiltration and kinetic aspects of a biotrickling filter for the removal of paint solvent mixture laden air stream. Journal Hazardous Materials, Vol.152, pp. 1027-1036, ISSN 0304-3894

Paca, J., Klapkova, E., Halecky, M., Jones, K. \& Webster, T.S. (2006). Interactions of hydrophobic and hydrophilic solvent component degradation in an air-phase biotrickling filter reactor. Environmental Progress, Vol.25, pp. 365-372, ISSN 19447450

Popescu, P. \& Ionel, I. (2010). Anthropogenic air pollution sources, In: Air quality, K. Ashok, (Ed.), 1-22, Sclyo, ISBN 978-953-307-131-2, Rijeka, Croatia

Sempere, F., Gabaldón, C., Martínez-Soria, V., Marzal, P., Penya-roja, J.M. \& ÁlvarezHornos, F.J. (2008). Performance evaluation of a biotrickling filter treating a mixture of oxygenated VOCs during intermittent loading. Chemosphere, Vol.73, pp. 1533-1539, ISSN 0045-6535

Shareefdeen, Z. \& Singh, A. (2005). Biotechnology for odor and air pollution control. Springer, ISBN 978-3-540-74049-0, Heidelberg, Germany

Steele, J.A., Ozis, F., Fuhrman, J.A. \& Devinny, J.S. (2005). Structure of microbial communities in ethanol biofilters. Chemical Engineering Journal, Vol.113, pp. 135-143, ISSN 1385-8947

Webster, T.S., Togna, A.P., Guarini, W.J. \& McKnight, L. (1999). Application of a biological trickling filter reactor to treat volatile organic compound emissions from a spray paint booth operation, Metal Finishing, Vol.97, pp. 20-26, ISSN 0026-0576

World Health Organization (2004). Health aspects of air pollution, WHO Regional Office for Europe, Copenhagen, Denmark

Wright, W.F., Schroeder, E.D. \& Chang, D.P.Y. (2005). Regular transient loading response in a vapor-phase flow-direction-switching biofilter. Journal Environmental Engineering, Vol.131, pp. 1649-1658, ISSN 0733-9372 


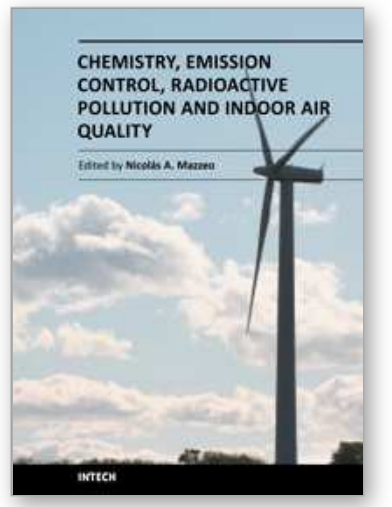

\author{
Chemistry, Emission Control, Radioactive Pollution and Indoor Air \\ Quality \\ Edited by Dr. Nicolas Mazzeo
}

ISBN 978-953-307-316-3

Hard cover, 680 pages

Publisher InTech

Published online 27, July, 2011

Published in print edition July, 2011

The atmosphere may be our most precious resource. Accordingly, the balance between its use and protection is a high priority for our civilization. While many of us would consider air pollution to be an issue that the modern world has resolved to a greater extent, it still appears to have considerable influence on the global environment. In many countries with ambitious economic growth targets the acceptable levels of air pollution have been transgressed. Serious respiratory disease related problems have been identified with both indoor and outdoor pollution throughout the world. The 25 chapters of this book deal with several air pollution issues grouped into the following sections: a) air pollution chemistry; b) air pollutant emission control; c) radioactive pollution and d) indoor air quality.

\title{
How to reference
}

In order to correctly reference this scholarly work, feel free to copy and paste the following:

F. Javier Álvarez-Hornos, Feliu Sempere, Marta Izquierdo and Carmen Gabaldón (2011). Lab-scale Evaluation of Two Biotechnologies to Treat VOC Air Emissions: Comparison with a Pilot Unit Installed in the Plastic Coating Sector, Chemistry, Emission Control, Radioactive Pollution and Indoor Air Quality, Dr. Nicolas Mazzeo (Ed.), ISBN: 978-953-307-316-3, InTech, Available from: http://www.intechopen.com/books/chemistryemission-control-radioactive-pollution-and-indoor-air-quality/lab-scale-evaluation-of-two-biotechnologies-totreat-voc-air-emissions-comparison-with-a-pilot-unit-

\section{INTECH}

open science | open minds

\section{InTech Europe}

University Campus STeP Ri

Slavka Krautzeka 83/A

51000 Rijeka, Croatia

Phone: +385 (51) 770447

Fax: +385 (51) 686166

www.intechopen.com

\section{InTech China}

Unit 405, Office Block, Hotel Equatorial Shanghai

No.65, Yan An Road (West), Shanghai, 200040, China

中国上海市延安西路65号上海国际贵都大饭店办公楼 405 单元

Phone: +86-21-62489820

Fax: $+86-21-62489821$ 
(C) 2011 The Author(s). Licensee IntechOpen. This chapter is distributed under the terms of the Creative Commons Attribution-NonCommercialShareAlike-3.0 License, which permits use, distribution and reproduction for non-commercial purposes, provided the original is properly cited and derivative works building on this content are distributed under the same license. 